\title{
Pd Supported IRMOF-3: Heterogeneous, Efficient and Reusable Catalyst for Heck Reaction
}

\author{
Ayat Nuri ${ }^{1,2} \cdot$ Nemanja Vucetic $^{2} \cdot$ Jan-Henrik Smått ${ }^{3}$ Yagoub Mansoori ${ }^{1} \cdot$ Jyri-Pekka Mikkola $^{2,4}$. \\ Dmitry Yu. Murzin² ${ }^{2}$
}

Received: 10 September 2018 / Accepted: 24 March 2019 / Published online: 4 April 2019

(c) The Author(s) 2019

\begin{abstract}
IRMOF-3 with a high surface area prepared by a hydrothermal method was used for deposition of Pd(OAc $)_{2}$ on IRMOF-3 particles. The final catalyst was characterized with FT-IR, nitrogen physisorption, thermogravimetry, scanning electron microscopy, transmission electron microscopy combined with energy dispersive X-ray analysis, wide angle X-ray diffraction spectroscopy and X-ray photoelectron spectroscopy. The prepared porous catalyst was effectively used in the Heck coupling reaction in the presence of an organic base. The reaction parameters such as the type of base, amounts of catalyst and solvents, temperature were optimized. The catalyst was then easily separated, washed, and reused 4 times without significant losses of catalytic activity.
\end{abstract}

\section{Graphical Abstract}

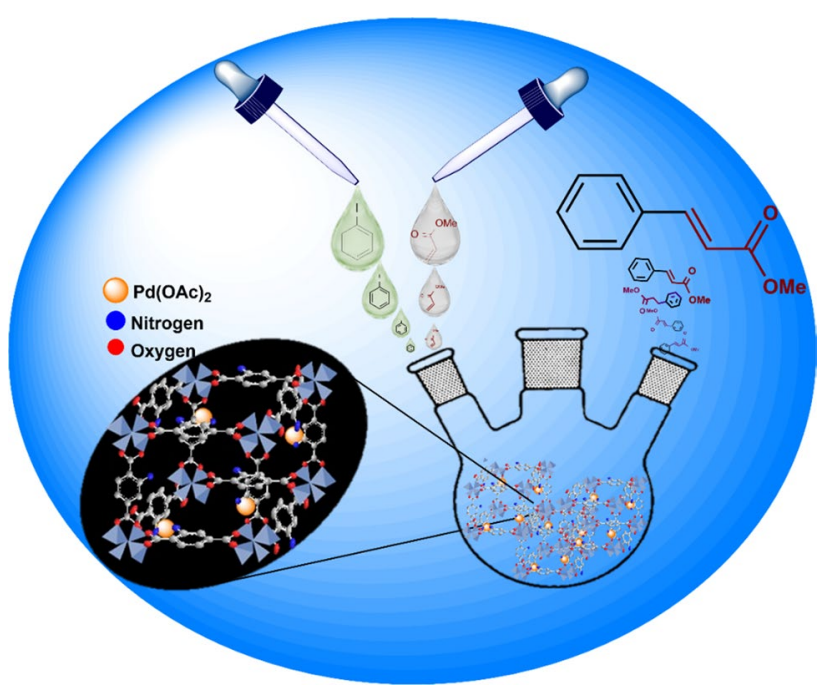

Keywords Metal-organic-frameworks $\cdot$ IRMOF-3-Pd $\cdot$ Heck reaction

Dmitry Yu. Murzin

dmurzin@abo.fi

Extended author information available on the last page of the article

\section{Introduction}

Recently metal-organic frameworks (MOFs), porous materials of a crystalline structure comprising bridged organic ligands and metal centers, have been attracted significant attention in gas sorption average owing to their large pore volumes and surface areas. Several studies have been 
reported on MOFs utilization as heterogeneous catalysts [1-4], in gas storage [5], separation [6], drug delivery [7], and sensing $[8,9]$. These materials have been explored because of their intrinsic high surface area, tunable pores, and various functionalities [10].

The IRMOF series based on MOF-5 was synthesized possessing octahedral clusters with carboxylate linear linkers. IRMOF-1 formed an oxide-centered $\mathrm{Zn}_{4} \mathrm{O}$ tetrahedron by six carboxylate edges giving the octahedral shape that reticulates into a three dimensional (3D) cubic porous system. The IRMOFs pore size and structure depend on the functional groups on the linkers. When the linkers have different functional groups such as bromo, amino, $n$-propoxy, $n$-pentoxy, cyclobutyl, and fused benzene, effective structures ranging from IRMOF-2 through IRMOF-7 (Fig. 1) can be synthesized [11]. Each of the different type of IRMOFs has a specific single-crystal X-ray diffraction spectroscopy (XRD) pattern.

A high flexibility of these compounds allows synthesis of several types of MOFs with ultrahigh surface area and high thermal stability. For example, in the case of MOF-5 decomposition of the structure happens at as high temperature region as between 350 and $400{ }^{\circ} \mathrm{C}$ [12]. In terms of the framework structure, the MOFs have different types such as extra-high porosity frameworks IRMOF-1, square channels (MOF-2), hexagonally packed cylindrical channels (MOF74), MOF-177, interpenetration (IRMOF-11), alkyl- and amino-functionalized pores (IRMOFs-6 and -3) and pores decorated with open metal sites (MOF-505 and $\mathrm{Cu}_{3}(\mathrm{BTC})_{2}$ ) [13]. Babarao et al. studied storage and separation of $\mathrm{CO}_{2}$ and $\mathrm{CH}_{4}$ with silicalite, $\mathrm{C}_{168}$ schwarzite, and IRMOF-1 [14]. The authors compared the materials and reported that IRMOF-1 has a considerably higher adsorption volume than other adsorbents, while the adsorption selectivity of $\mathrm{CO}_{2}$ over $\mathrm{CH}_{4}$ was found to be similar. IRMOF-14 and IRMOF16 being nontoxic were found to afford high-loading capacity for drug delivery. The results showed that the hydrogen atom with a hydroxyl moiety in the organic linker of IRMOF-14 and IRMOF-16 is the key for hydrogen bonding and acid-base interactions with Tamoxifen [15]. Phan et al. synthesized a highly porous IRMOF-3 from the reaction of zinc nitrate hexahydrate and 2-amino-1,4-benzenedicarboxylic acid by a solvothermal technique. This catalyst was used for the Paal-Knorr reaction of benzyl amine with 2,5-hexanedione confirming that IRMOF- 3 is an efficient heterogeneous catalyst to form 1-benzyl-2,5-dimethyl- $1 H$-pyrrole as the major product [16].

Several techniques have been developed for coupling of $\mathrm{C}-\mathrm{C}$ bond, which can be exemplified by Heck [17], Suzuki [18], Negishi [19], Sonogashira [20], Kumada [21], and Stille[22] coupling reactions, etc. Various metals such as palladium, rhodium, ruthenium, copper, zinc, tin, magnesium, etc [23]. have been used. One of the fundamental transformations in organic chemistry is the Heck reaction used for reacting substituted halobenzenes and vinyl halides with olefins (Scheme 1). In general, the reaction of alkyl
Fig. 1 Structure of IRMOF materials

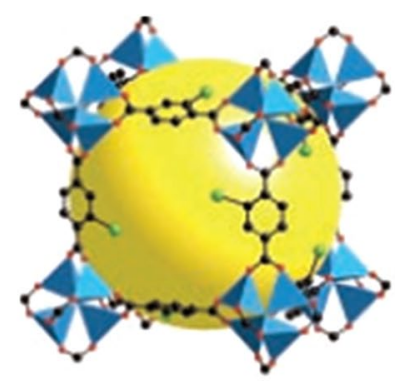

IRMOF-2

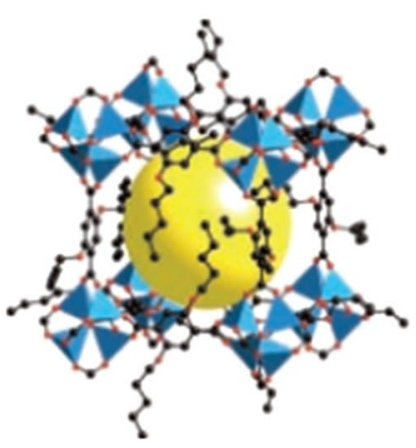

IRMOF-5

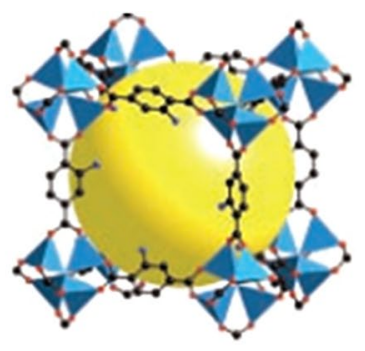

IRMOF-3
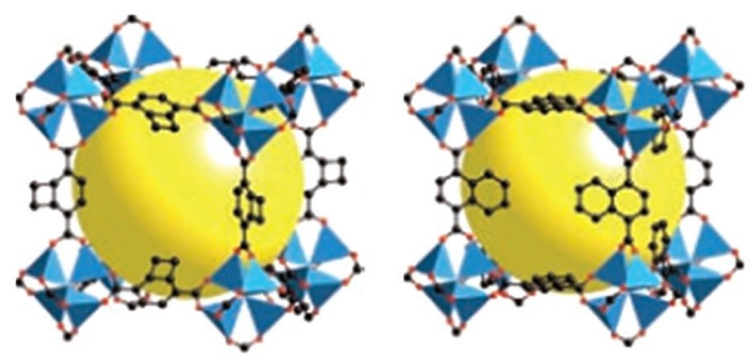

IRMOF-6

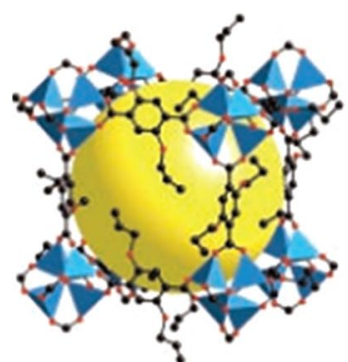

IRMOF-4

IRMOF-7 
Scheme 1 Scheme of the Heck reaction

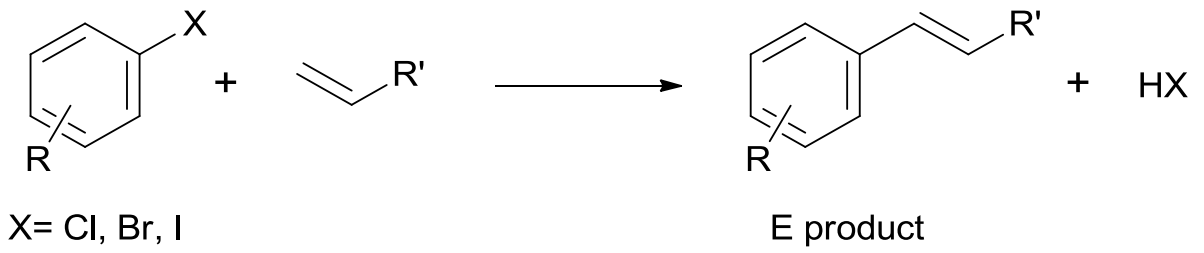

halides with olefins is not satisfactory, because of a premature $\beta$-hydrogen elimination and slow oxidative addition rates [24]. Challenges to enhance the scope of enantioselective Heck reactions have been very recently well documented [25]. Kong et al. reported palladium-catalyzed intramolecular asymmetric enantioselective Heck reactions in the presence of diboron-water as a hydride source [26]. Bao et al. described palladium-catalyzed enantioselective Narasaka-Heck reaction in the presence of an achiral bidentate phosphine ligand with direct $\mathrm{C}-\mathrm{H}$ alkylation of arenes [27].

A highly effective tool for deposition of various metals including palladium and platinum is chemical vapor deposition of organometallic compounds. Sabo et al. deposited palladium into a highly porous metal-organic framework MOF-5 by palladium acetoacetate in $\mathrm{CHCl}_{3}$ solution via the "incipient wetness" impregnation and studied catalytic behavior in styrene hydrogenation. Park et al. prepared a highly dispersed palladium (II) in a defective metal-organic framework for $\mathrm{C}-\mathrm{H}$ activation and functionalization of naphthalene [28].

In this work deposition of palladium acetate on the surface of IRMOF-3 was performed to develop a highly active and reusable heterogeneous catalyst for the Heck coupling reaction.

\section{Experimental}

\subsection{Materials}

Zinc nitrate hexahydrate, 2-aminoterephthalic acid, $\operatorname{Pd}(\mathrm{OAc})_{2}$, iodobenzene, ethyl acrylate and bases were obtained from Sigma Aldrich and used without further purification. Other solvents and chemicals were of laboratory grade, obtained from Alfa and used without further purification.

\subsubsection{Preparation of IRMOF-3}

In order to synthesize IRMOF-3, zinc nitrate hexahydrate $(3.720 \mathrm{~g}, 12.5 \mathrm{mmol})$ and 2-aminoterephthalic acid $(0.750 \mathrm{~g}, 4.15 \mathrm{mmol})$ were dissolved in dry DMF $(100 \mathrm{~mL})$. The mixture was placed into an autoclave heated at $100{ }^{\circ} \mathrm{C}$ for $24 \mathrm{~h}$, following by slow cooling to room temperature. The solid products after filtration were washed three times with DMF. For removal of DMF from the pores immersion two times into $\mathrm{CH}_{2} \mathrm{Cl}_{2}$ for $12 \mathrm{~h}$ was done $[29,30]$.

\subsubsection{Preparation of IRMOF-3-Pd}

Activated IRMOF-3 particles (1.000 g) were dispersed in $\mathrm{CH}_{2} \mathrm{Cl}_{2}(30 \mathrm{~mL})$, following by addition of $\mathrm{Pd}(\mathrm{OAc})_{2}(50$ $\mathrm{mg}$ ) and stirring for $24 \mathrm{~h}$. Thereafter, the solid catalyst was separated by centrifugation and washed several times with $\mathrm{CH}_{2} \mathrm{Cl}_{2}$ and dried under vacuum at $150{ }^{\circ} \mathrm{C}$ for $24 \mathrm{~h}$ to give IRMOF-3-Pd (3.5 wt\% Pd detected by ICP-OES) [31]. The procedure for the catalyst synthesis is given in Scheme 2.

\subsection{Characterization}

The functional groups on the solid compounds were investigated by infrared spectroscopy (ATI Mattson FTIR). The specific surface area and pore volume were determined by $\mathrm{N}_{2}$ adsorption/desorption using a Sorptometer 1900 apparatus (Carlo-Erba Instruments). The morphology and crystal size distribution were studied by a scanning electron microscope (Zeiss Leo 1530 Gemini) equipped with a Thermo-NORAN vantage X-ray detector. Elemental analysis was performed with the same instrument. The IRMOF-3 and IRMOF3-Pd size distributions images were obtained by transmission electron microscopy (TEM) using by EFTEM, LEO 912 OMEGA, LaB6 filament, $120 \mathrm{kV}$. Thermogravimetry (TGA) curves were recorded on a CAHN D-200 instrument for the powder samples (scanning rate $10^{\circ} \mathrm{C} / \mathrm{min}$ to $600{ }^{\circ} \mathrm{C}$ ). The content of palladium in the catalyst was determined by inductively coupled plasma-optical emission spectroscopy (ICP-OES), using an Optima 4300 DV optical atomic emission spectrometer. The XRD measurements were carried out on a Bruker AXS D8 Discover instrument equipped with a $\mathrm{Cu} \mathrm{K}{ }_{\alpha} \mathrm{X}$-ray source and scintillator point detector. The samples were scanned in the $1^{\circ}-70^{\circ} 2 \theta$ range, with an increment of $0.04^{\circ}$ and at a scan speed of $8 \mathrm{~s}$ per point. The progress of the reaction was analyzed by GC equipped with FID system using HP 6890 Series with HP-5, 5\% phenyl methyl siloxane capillary column $(30.0 \mathrm{~m} \times 320 \mu \mathrm{m}, 0.25 \mu \mathrm{m})$. The injector temperature was $280^{\circ} \mathrm{C}$, while the gas flow was $9.5 \mathrm{~mL} / \mathrm{min}$. Hexadecane was used as an internal standard. 


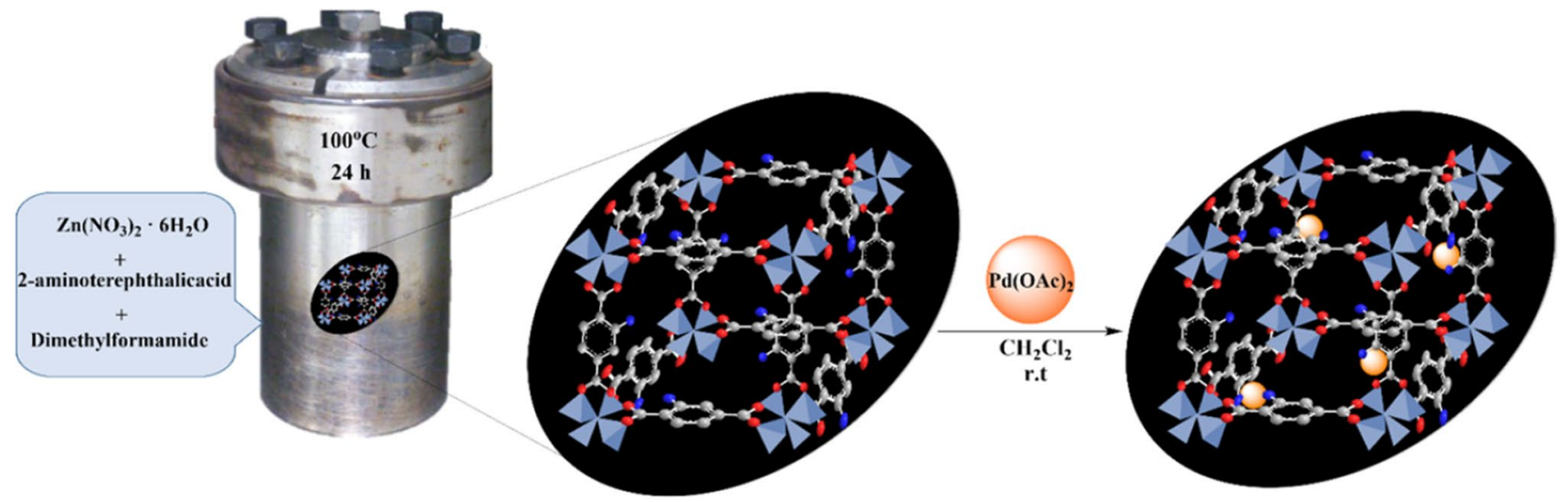

Scheme 2 Preparation of IRMOF-3-Pd

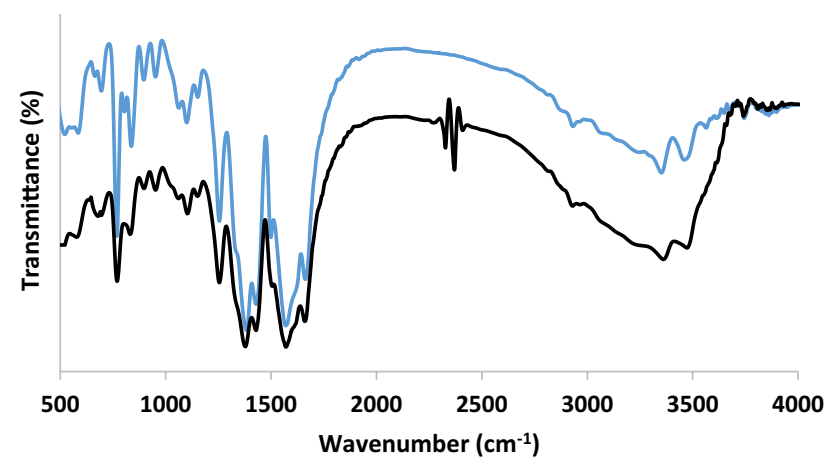

Fig. 2 FT-IR spectra for IRMOF-3 (black line) and IRMOF-3-Pd (blue line)

\subsection{Heck Coupling Reaction}

The reaction was performed at $120{ }^{\circ} \mathrm{C}$ in the $14 \mathrm{~mL}$ round bottom vial with stirrer. The reaction mixture contained $0.2 \mathrm{mmol}$ of iodobenzene, $0.3 \mathrm{mmol}$ of methyl acrylate, $0.3 \mathrm{mmol}$ of triethylamine $\left(\mathrm{Et}_{3} \mathrm{~N}\right), 0.001 \mathrm{~g}$ of IRMOF-3-Pd as a catalyst $(0.165 \mathrm{~mol} \%$ Pd to aryl halide $)$ and $0.5 \mathrm{~mL}$ DMA (dimethylacetamide) as a solvent. The reaction progress was followed by TLC and after completion analyzed with GC. The catalyst was separated from the reaction mixture by filtration and then it was washed with DMA and ethyl acetate.

\section{Results and Discussion}

\subsection{Catalyst Characterization}

IRMOF-3 was studied using different characterization techniques. In the FT-IR spectra characteristic bands revealed the presence of functional organic groups on IRMOF-3 and IRMOF-3-Pd as shown in Fig. 2. The peaks of asymmetric and symmetric stretching vibrations of amino groups are visible at 3477 and $3355 \mathrm{~cm}^{-1}$. The strong bands at $1662-1382 \mathrm{~cm}^{-1}$ are related to symmetrical and asymmetrical $\mathrm{O}-\mathrm{C}=\mathrm{O}$ vibrations of dicarboxylate and $\mathrm{C}=\mathrm{C}$ in the benzene ring. A strong peak at $1255 \mathrm{~cm}^{-1}$ is assigned to $\mathrm{C}-\mathrm{N}$ stretching. The aromatic $\mathrm{C}-\mathrm{H}$ bending at 1103 and $833 \mathrm{~cm}^{-1}$ also appeared in the spectra of IRMOF-3 [32, 33].

The SEM images show that the IRMOF-3 is highly crystalline displaying well-shaped cubic crystals (Fig. 3a-c). After deposition of palladium acetate on the surface, the cubic structures have been partially destroyed (Fig 3d, e).

In order to identify the elemental composition of IRMOF3-Pd EDX at random points on the surface of the catalyst was performed (Fig. 4). The EDX results indicate that palladium deposited on catalyst are at least to some extent ligated with chlorines that originates from $\mathrm{CH}_{2} \mathrm{Cl}_{2}$ that was used during catalyst preparation.

The measurements confirmed the presence of palladium, zinc, oxygen, nitrogen and carbon in the supported catalyst. The weight $\%$ and atomic $\%$ of different components are shown in Table 1.

Transmission electron microscopy (TEM) was performed to determine the MOF particle size. The porous structure of the IRMOF-3 is clearly visible in the TEM images (Fig. 5a, b). After deposition of palladium acetate on IRMOF-3, palladium (II) has been converted into metallic palladium, which is visible as the metal clusters with the size below ca. $6 \mathrm{~nm}$ (Fig. 5c). These clusters tend to grow. After four Heck cycles they formed much bigger agglomerates (Fig 5d) which probably caused drop of the activity.

The nitrogen adsorption-desorption isotherms for IRMOF-3 is shown in Fig. 6. The BET surface area for IRMOF-3 was calculated to be $996 \mathrm{~m}^{2} / \mathrm{g}$. After deposition of palladium on the surface of IRMOF-3 the surface area was diminished to $810 \mathrm{~m}^{2} / \mathrm{g}$. The Pd loading was optimized to keep IRMOF-3 structure and high porosity. 


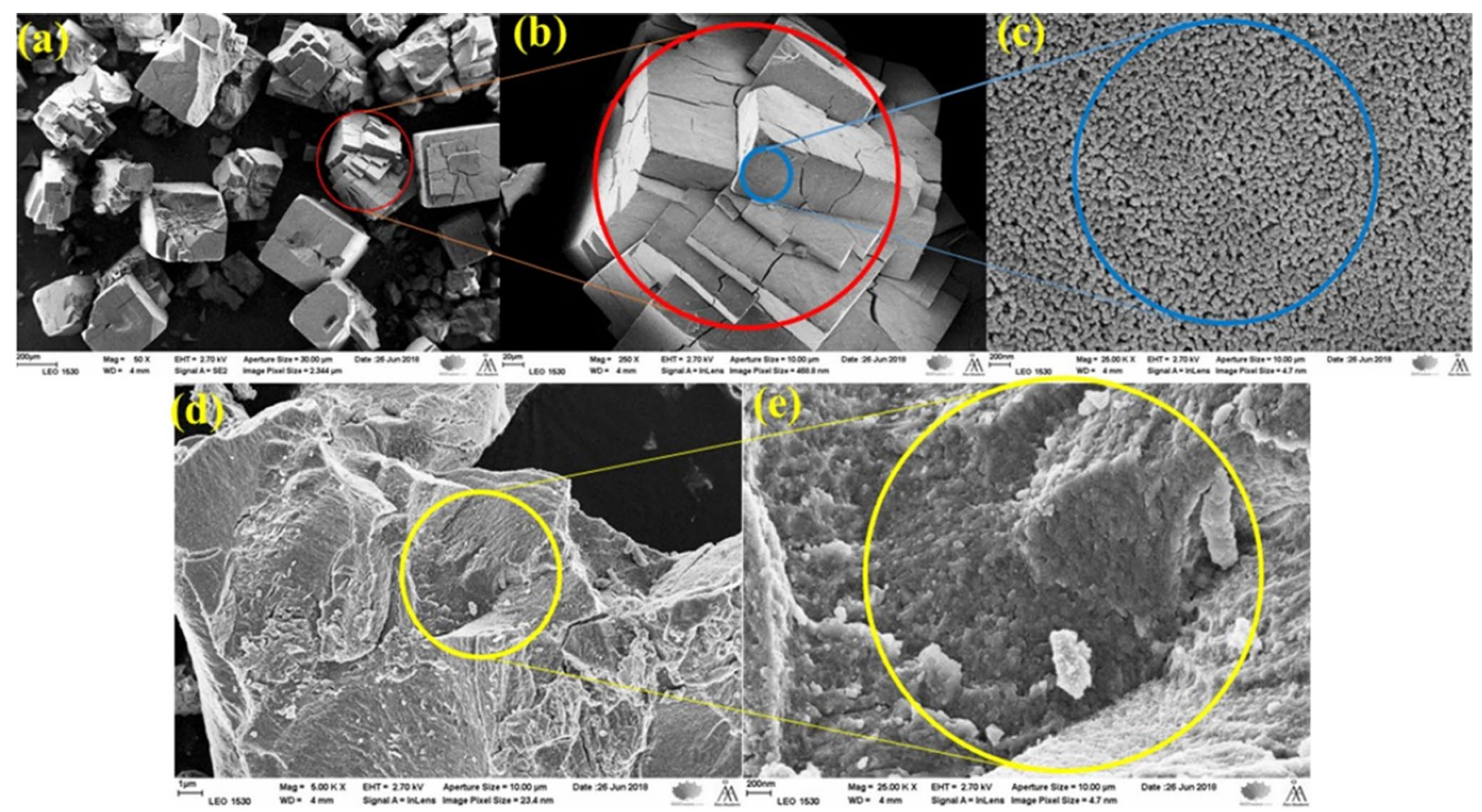

Fig. 3 SEM images for IRMOF-3 (a to c) and IRMOF-3-Pd (d and e)

Fig. 4 EDX analysis of IRMOF-3-Pd

Table 1 The weight $\%$ and atomic $\%$ of elements in the catalyst

Low angle X-ray diffraction (XRD) patterns of IRMOF-3 and IRMOF-3-Pd are presented in Fig. 7a. Diffraction peaks of the supporting material (Fig. 7a-black pattern) were observed at $2 \theta=6.8,9.8$ and 13.8 which is in agreement with the structure of IRMOF-3 [34]. After palladium

\begin{tabular}{lrr}
\hline Element & wt $\%$ & \multicolumn{1}{c}{ at.\% } \\
\hline Carbon & 52.23 & 64.17 \\
Nitrogen & 1.51 & 1.60 \\
Oxygen & 33.05 & 30.48 \\
Zinc & 10.34 & 2.33 \\
Palladium & 1.09 & 0.15 \\
\hline
\end{tabular}

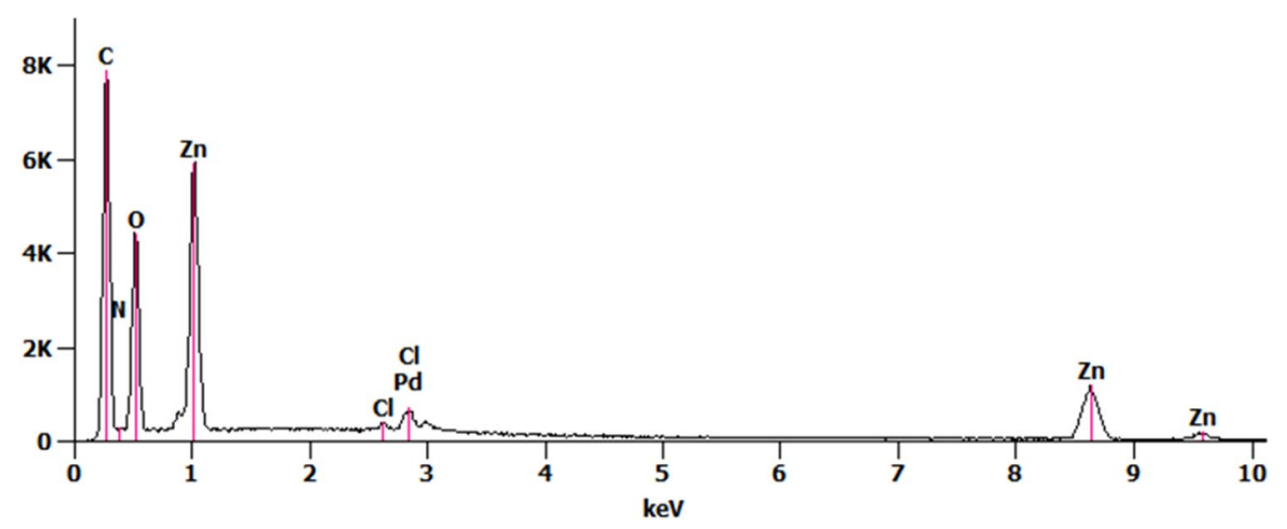

deposition the intensity of peaks has been slightly decreased but they were still present showing that the crystal structure of IRMOF-3 is preserved (Fig. 7a-red pattern). However, after the reaction only the peak of a lower intensity at the $2 \theta=9.8$ indicating that framework was preserved only to a certain extent (Fig. 7b).

The thermogravimetric analysis (Fig. 8) reflects the thermal stability of IRMOF-3. The IRMOF-3 exhibited two main weight losses, the first one (app. 7\%) in the temperature range below $400{ }^{\circ} \mathrm{C}$, corresponding to the loss of water from the pores of metal organic frameworks as well as aromatic groups and unreacted molecules. A second more prominent mass loss of $27 \%$ above $400{ }^{\circ} \mathrm{C}$ is related to decomposition of the organic frameworks. 


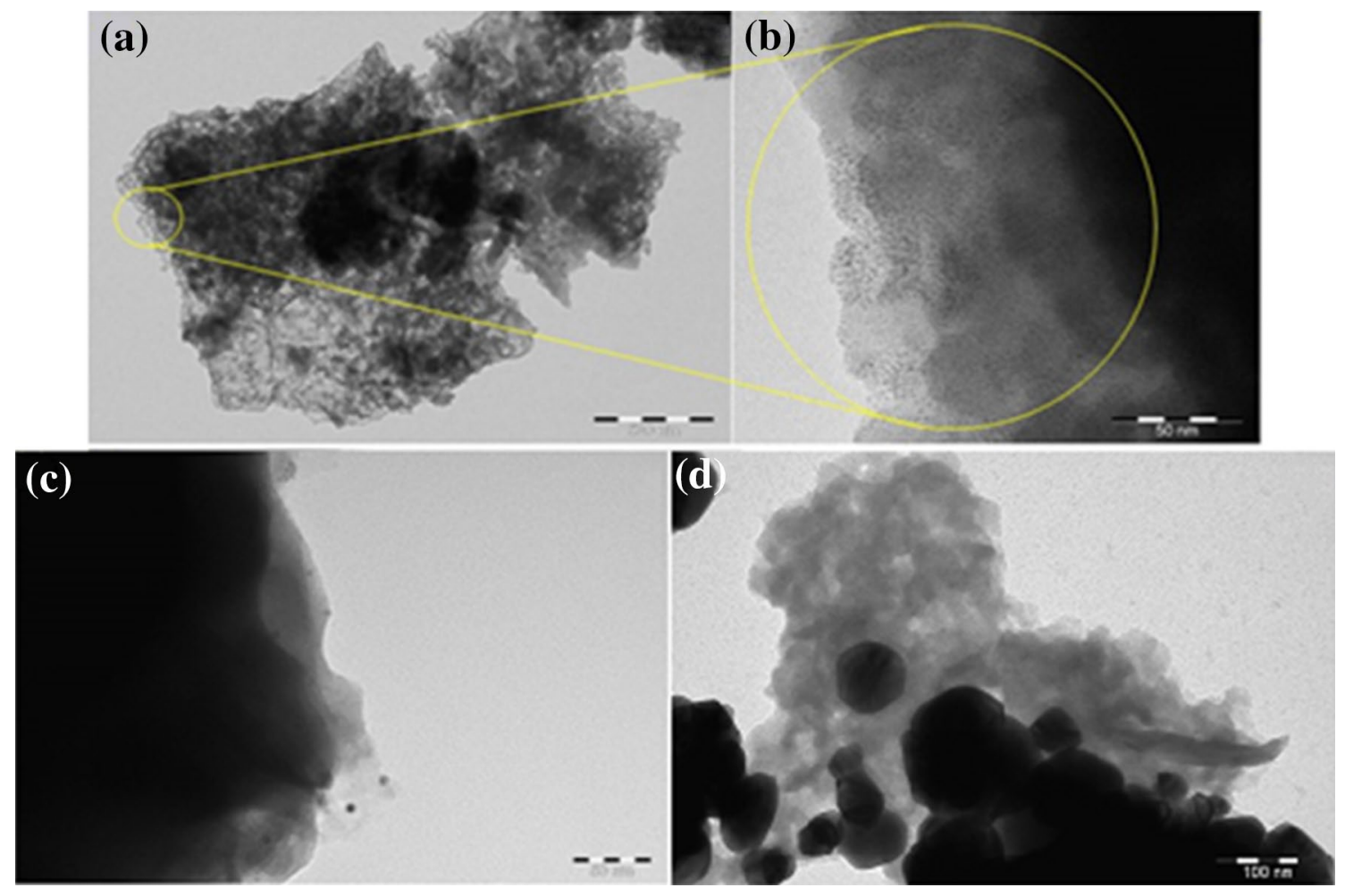

Fig. 5 TEM images for fresh IRMOF-3-Pd (a to c) and used (d)

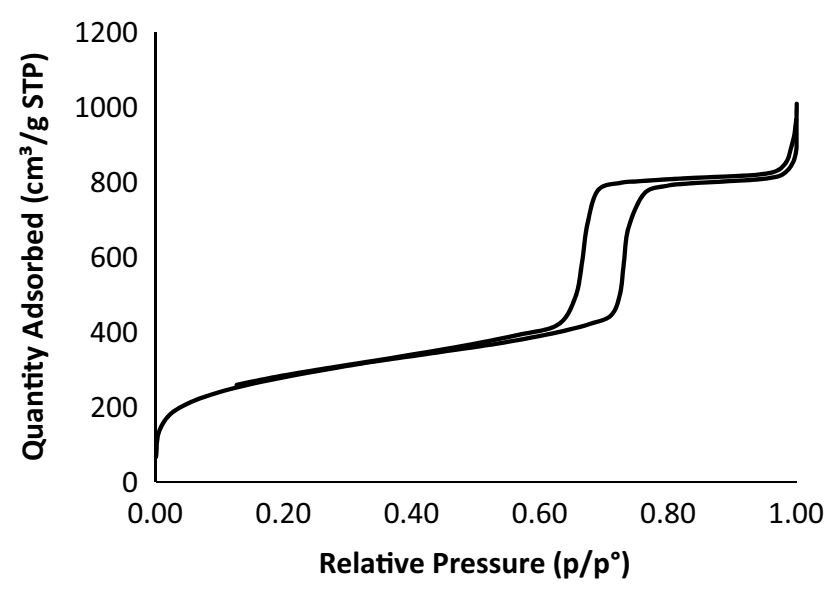

Fig. 6 Nitrogen physisorption diagram of IRMOF-3

X-ray photoelectron spectroscopy (XPS) analysis, giving information on the metal oxidation state, is presented in Fig. 9a, which displays that the fresh catalyst contains palladium in the form of $\mathrm{Pd}(\mathrm{II})$ having the characteristic $3 \mathrm{~d}_{5 / 2}$ and $3 d_{3 / 2}$ peaks at 337.6 and $342.9 \mathrm{eV}$ binding energies. After the reaction (Fig. 9b) all $\mathrm{Pd}$ was converted to the metallic $\mathrm{Pd}(0)$ form with binding energies at 335.7 and $340.9 \mathrm{eV}$, in agreement with TEM analysis. Besides these peaks, an additional peak at around $343.8 \mathrm{eV}$ was observed, being evidently more prominent in the spectra of the recycled catalyst. It can be speculated that this peak originates from Pd forming an alloy with zinc which can result in significant electron disorder similar to previous reports $[35,36]$.

\subsection{Optimization of Reaction Conditions}

The reaction conditions were optimized by conducting the coupling reaction of iodobenzene and methyl acrylate, as model substances, and changing the reaction parameters including the base type, the solvent, the catalyst amount and reaction temperature. The results are summarized in Table 2. Methyl acrylate is typically added in excess [37] to compensate evaporation, moreover unreacted iodobenzene in the reaction mixture causes high leaching of palladium from the catalyst [38]. Experiments with various solvents (entry 1-10) revealed that dimethylacetamide (DMA) was the most efficient solvent (entry 1,3.6\% yield). After a careful screening of different bases (entries 11 to 18 ), $\mathrm{Et}_{3} \mathrm{~N}$ was found to give the highest yield of the coupling product (entry $15,88.8 \%$ yield). Solubility of the inorganic bases is very poor in the organic systems, while triethylamine is miscible in the slurry of the Heck reaction. This is the main reason for high conversion in the presence of triethylamine as a base [39]. Additionally, commonly used Heck solvents such as DMF and NMP are tested with $\mathrm{Et}_{3} \mathrm{~N}$ base to avoid any 

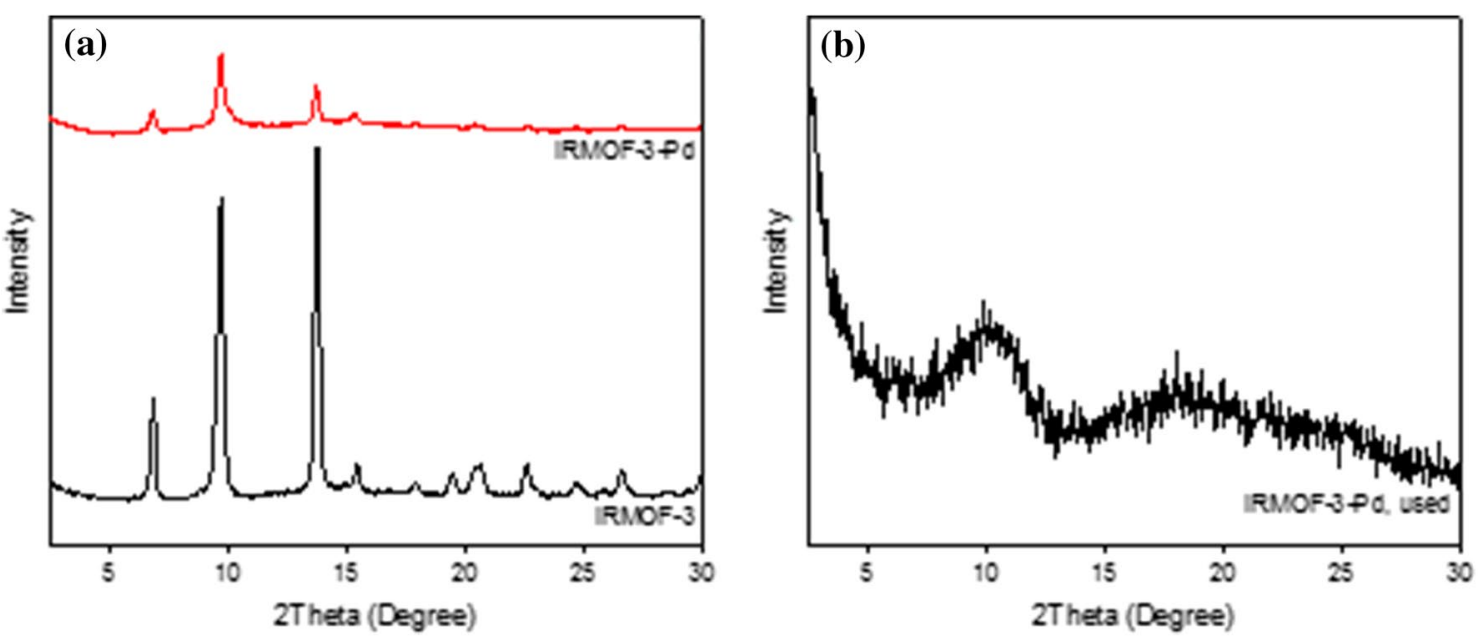

Fig. 7 XRD patterns of IRMOF-3, IRMOF-3-Pd (a) and IRMOF-3-Pd recycled (b)

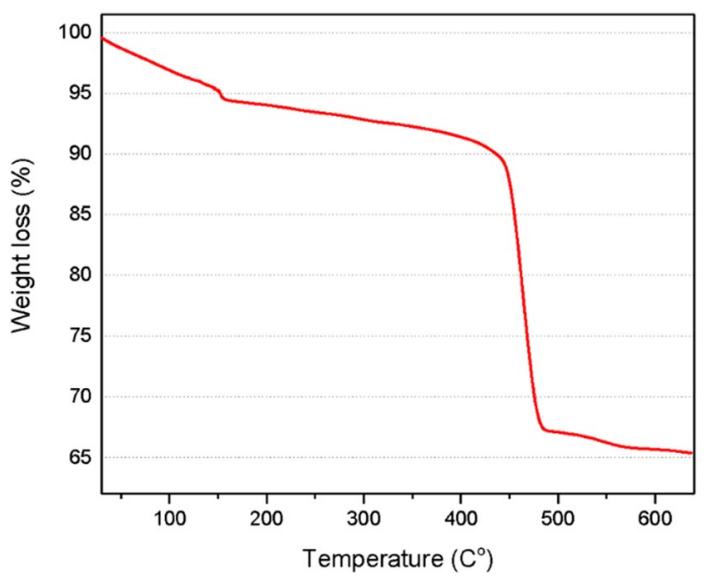

Fig. 8 TGA thermograms of IRMOF-3

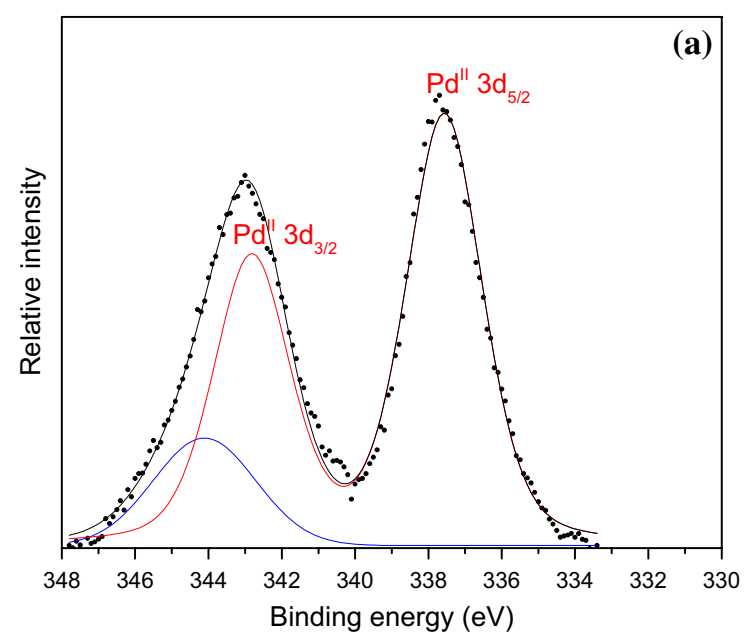

Fig. 9 XPS spectra of the fresh and recycled IRMOF-3-Pd

uncertainty with choice of solvent/base system (entries 19, 20). The effect of Pd loading was investigated showing that the highest activity was observed by using $0.165 \mathrm{~mol} \%$ of palladium (entry 21, 5.2\% yield). Based on plotted results for different catalyst amounts (Fig. 10a) the reaction order in the catalyst was calculated to be 0.70 . A deviation from first order kinetics is expected due to formation of inactive palladium dimers when a relatively high $\mathrm{Pd}$ to halide ratio is used. Smaller amounts of palladium than used in the current work would probably lead to the first order reaction, however, such small amounts are very difficult to handle experimentally. The reaction order in the catalyst determined in the current work is in good agreement with a recently published kinetic study by Bures, who reported the values of 0.55-0.86 depending on Pd loading [40]. Furthermore, by

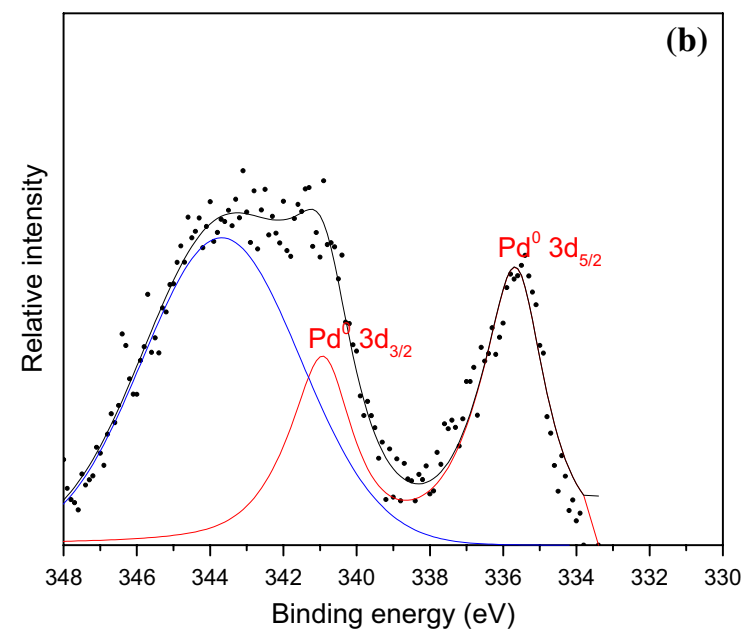


Table 2 Optimization of conditions for Heck reaction

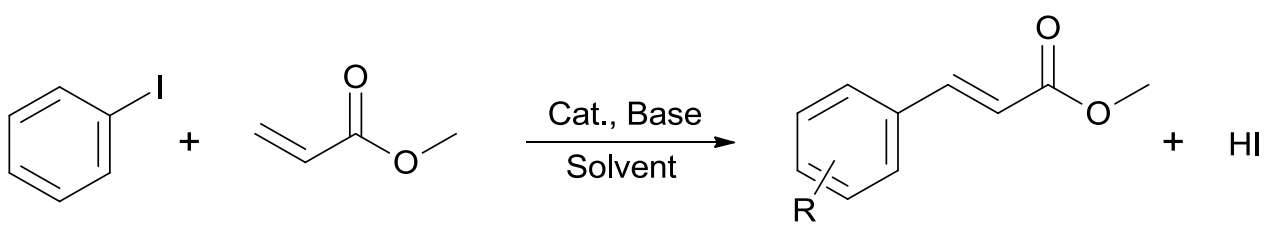

\begin{tabular}{|c|c|c|c|c|c|c|}
\hline Entry & Solvent & $\mathrm{Pd}(\mathrm{mol} \%)$ & Base & Temperature $\left({ }^{\circ} \mathrm{C}\right)$ & Time (min) & Yield $(\%)^{\mathrm{b}}$ \\
\hline 1 & DMA & 0.165 & $\mathrm{~K}_{2} \mathrm{CO}_{3}$ & 80 & 30 & 3.6 \\
\hline 2 & DMSO & 0.165 & $\mathrm{~K}_{2} \mathrm{CO}_{3}$ & 80 & 30 & 0 \\
\hline 3 & DMF & 0.165 & $\mathrm{~K}_{2} \mathrm{CO}_{3}$ & 80 & 30 & 0 \\
\hline 4 & NMP & 0.165 & $\mathrm{~K}_{2} \mathrm{CO}_{3}$ & 80 & 30 & 0 \\
\hline 5 & $\mathrm{H}_{2} \mathrm{O}$ & 0.165 & $\mathrm{~K}_{2} \mathrm{CO}_{3}$ & 80 & 30 & 0 \\
\hline 6 & Toluene & 0.165 & $\mathrm{~K}_{2} \mathrm{CO}_{3}$ & 80 & 30 & 0 \\
\hline 7 & Dioxan & 0.165 & $\mathrm{~K}_{2} \mathrm{CO}_{3}$ & 80 & 30 & 0 \\
\hline 8 & $\mathrm{EtOH}$ & 0.165 & $\mathrm{~K}_{2} \mathrm{CO}_{3}$ & 80 & 30 & 0 \\
\hline 9 & $\mathrm{CH}_{3} \mathrm{CN}$ & 0.165 & $\mathrm{~K}_{2} \mathrm{CO}_{3}$ & 80 & 30 & 1.6 \\
\hline 10 & Acetone & 0.165 & $\mathrm{~K}_{2} \mathrm{CO}_{3}$ & 80 & 30 & 0 \\
\hline 11 & DMA & 0.165 & $\mathrm{~K}_{2} \mathrm{CO}_{3}$ & 100 & 30 & 13.6 \\
\hline 12 & DMA & 0.165 & $\mathrm{Cs}_{2} \mathrm{NO}_{3}$ & 100 & 30 & 3.5 \\
\hline 13 & DMA & 0.165 & $\mathrm{Cs}_{2} \mathrm{CO}_{3}$ & 100 & 30 & 7.6 \\
\hline 14 & DMA & 0.165 & HMTA $^{\mathrm{a}}$ & 100 & 30 & 27.1 \\
\hline 15 & DMA & 0.165 & DBU & 100 & 30 & Trace \\
\hline 16 & DMA & 0.165 & $\mathrm{NaOAc}$ & 100 & 30 & 9 \\
\hline 17 & DMA & 0.165 & free & 100 & 30 & 4.5 \\
\hline 18 & DMA & 0.165 & $\mathrm{Et}_{3} \mathrm{~N}$ & 100 & 30 & 88.8 \\
\hline 19 & DMF & 0.165 & $\mathrm{Et}_{3} \mathrm{~N}$ & 100 & 30 & 54 \\
\hline 20 & NMP & 0.165 & $\mathrm{Et}_{3} \mathrm{~N}$ & 100 & 30 & 81.9 \\
\hline 21 & DMA & 0.165 & $\mathrm{Et}_{3} \mathrm{~N}$ & 80 & 15 & 5.2 \\
\hline 22 & DMA & 0.33 & $\mathrm{Et}_{3} \mathrm{~N}$ & 80 & 15 & 8.4 \\
\hline 23 & DMA & 0.5 & $\mathrm{Et}_{3} \mathrm{~N}$ & 80 & 15 & 11.2 \\
\hline 24 & DMA & Free & $\mathrm{Et}_{3} \mathrm{~N}$ & 80 & 15 & 0 \\
\hline 25 & DMA & 0.165 & $\mathrm{Et}_{3} \mathrm{~N}$ & 90 & 15 & 50.3 \\
\hline 26 & DMA & 0.165 & $\mathrm{Et}_{3} \mathrm{~N}$ & 100 & 15 & 56.3 \\
\hline 27 & DMA & 0.165 & $\mathrm{Et}_{3} \mathrm{~N}$ & 120 & 15 & 87.5 \\
\hline 28 & DMA & 0.165 & $\mathrm{Et}_{3} \mathrm{~N}$ & 140 & 15 & 100 \\
\hline
\end{tabular}

Reaction conditions: iodobenzene $(0.2 \mathrm{mmol})$, methyl acrylate $(0.3 \mathrm{mmol})$, IRMOF-3-Pd as catalyst, solvent $(0.5 \mathrm{~mL})$ and base $(0.3 \mathrm{mmol})$

${ }^{a}$ Hexamethylenediamine

${ }^{\mathrm{b}} \mathrm{GC}$ yield

increasing the reaction temperatures (entries 25 to 28) reaction rate increases linearly which is explained typically by Arrhenius type dependence of the rate constants on temperature as well as by a faster redisposition of Pd on the catalyst at elevated temperature [41]. The apparent activation $\mathrm{C}_{\mathrm{Pd}}$ energy (Fig. 10b) was calculated to be $18.4 \mathrm{~kJ} / \mathrm{mol}$.

Without any catalyst the reaction between iodobenzene and methyl acrylate did not give any product (Entry 24).

In Table 3, the catalytic activity of the IRMOF-3-Pd in the Heck cross-coupling reaction of iodobenzene with methyl acrylate is compared with some catalysts reported in the literature. As can be seen, IRMOF-3-Pd is more effective than the previously studied catalysts for the Heck reaction. It should be also noted that the values of TOF presented for IRMOF-3-Pd (Table 3, entry 6), as well as for some other entries in the same Table (entries 1-3) certainly underestimate the real catalytic activity especially during the initial period, as they are calculated at $100 \%$ conversion.

Catalyst recyclability is one of the important factors in catalysis. In this respect, leaching of palladium, stability 
Fig. 10 Rate of the reaction between iodobenzene and methyl acrylate as a function of catalyst concentration (a) and temperature (b)
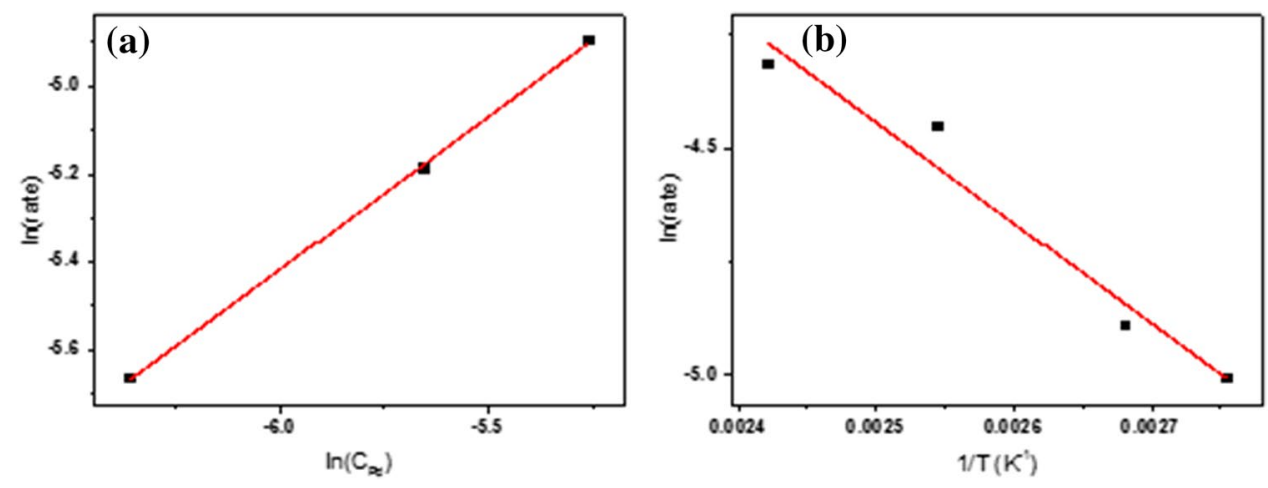

Table 3 Comparison of the prepared catalyst with other catalysts for Heck crosscoupling reactions from iodobenzene with methyl acrylate

\begin{tabular}{llllll}
\hline Entry & Catalyst & Time (h) & $\mathrm{T}\left({ }^{\circ} \mathrm{C}\right)$ & Yield $(\%)$ & $\mathrm{TOF}^{\left(\mathrm{h}^{-1}\right)^{\mathrm{b}}}$ \\
\hline 1 & $\mathrm{Pd} / \mathrm{SiO}_{2}[38]$ & 0.5 & 140 & 100 & 714 \\
2 & $\mathrm{Pd} / \mathrm{C} \mathrm{[38]}$ & 0.5 & 140 & 100 & 714 \\
3 & Palladacycle [41] & 0.3 & 140 & 100 & 602 \\
4 & $\mathrm{Pd} / \mathrm{C}$ particles [42] & 24 & 100 & 37 & 0.31 \\
5 & $\mathrm{Pd}(\mathrm{OAc})_{2}$ (ligand free) [43] & 1.5 & 80 & 91 & 60 \\
6 & $\mathrm{IRMOF-3-Pd}^{\mathrm{a}}$ & 0.25 & 140 & 100 & 2430 \\
\hline
\end{tabular}

${ }^{\mathrm{a}}$ This work

${ }^{\mathrm{b}} \mathrm{TOF}=$ the number of moles of reactant converted/(the number of moles of palladium $\times$ time $(\mathrm{h})$ )

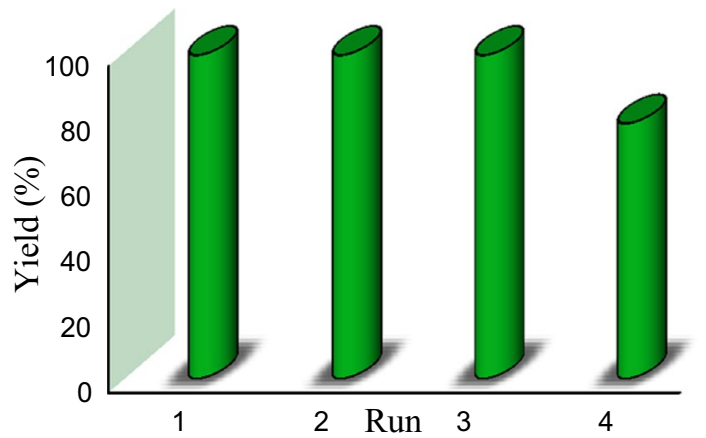

Fig. 11 Recycling of IRMOF-3-Pd for the Heck cross-coupling under optimal conditions. The reaction mixture contained $0.2 \mathrm{mmol}$ of iodobenzene, $0.3 \mathrm{mmol}$ of methyl acrylate, $0.3 \mathrm{mmol}^{\circ} \mathrm{Et}_{3} \mathrm{~N}, 0.001 \mathrm{~g}$ of IRMOF-3-Pd as a catalyst ( $0.165 \mathrm{~mol} \%$ Pd to aryl halide) and 0.5 mL DMA (dimethylacetamide) as a solvent

and reusability of supported IRMOF-3-Pd was studied in the Heck cross-coupling reaction of iodobenzene and methyl acrylate as a model substrate under optimal conditions. In order to reuse the catalyst, the IRMOF-3-Pd was separated by centrifuge after each cycle, washed with diethyl ether and ethyl acetate. A certain decline in activity can be seen (Fig. 11), which most probably can be attributed to palladium agglomeration (Fig. 5d) and leaching. In the first cycle $17 \%$ of Pd leached in the mixture of the reaction. Such leaching is in line with the current mechanistic views on the Mizoroki-Heck reaction with heterogeneous catalysts [44-46] suggesting that the reaction involves dissolution of $\mathrm{Pd}$ from the support with subsequent redeposition of formed $\mathrm{Pd}$ species in the solution. The latter colloidal type of species are thus considered catalytically active.

\section{Conclusions}

In the present study, IRMOF-3 was prepared by a hydrothermal method and after deposition of palladium acetate, was used as a heterogeneous catalyst for the Heck crosscoupling reaction. IRMOF-3 and IRMOF-3-Pd were characterized by FT-IR, nitrogen physisorption, transmission electron microscopy (TEM), scanning electron microscopy (SEM) combined with energy dispersive $\mathrm{X}$-ray analysis (EDX), broad angle X-ray diffraction spectroscopy (XRD) and X-ray photoelectron spectroscopy (XPS). The results have demonstrated that the IRMOF- 3 is a suitable support for deposition of palladium acetate, which can efficiently catalyze the Heck reaction between iodobenzene and methyl acrylate.

Acknowledgements Open access funding provided by Abo Akademi University (ABO). This work is part of the activities at the Ảbo Akademi University Johan Gadolin Process Chemistry Centre within the Centre of Excellence Programme appointed by ÅU, Finland. In Sweden the Bio 4 Energy programme is acknowledged. 


\section{Compliance with Ethical Standards}

Conflict of interest All authors claim no conflict of interest.

Open Access This article is distributed under the terms of the Creative Commons Attribution 4.0 International License (http://creativeco mmons.org/licenses/by/4.0/), which permits unrestricted use, distribution, and reproduction in any medium, provided you give appropriate credit to the original author(s) and the source, provide a link to the Creative Commons license, and indicate if changes were made.

\section{References}

1. Bhattacharjee S, Yang D-A, Ahn W-S (2011) A new heterogeneous catalyst for epoxidation of alkenesvia one-step post-functionalization of IRMOF-3 with a manganese(ii) acetylacetonate complex. Chem Commun 47:3637-3639

2. Dhakshinamoorthy A, Asiri A, Garcia H (2015) Mmetalorganic frameworks catalyzed C-C and C-heteroatom coupling reactions. Chem Soc Rev 44:1922-1947

3. Dhakshinamoorthy A, Li Z, Garcia H (2018) Catalysis and photocatalysis by metal organic frameworks. Chem Soc Rev 47:8134-8172

4. Chughtai A, Ahmad N, Younus H, Laypkov A, Verpoort F (2015) Metal-organic frameworks: versatile heterogeneous catalysts for efficient catalytic organic transformations. Chem Soc Rev 44:6804-6849

5. DeSantis D, Mason JA, James BD, Houchins C, Long JR, Veenstra M (2017) Techno-economic analysis of metal-organic frameworks for hydrogen and natural gas storage. Energy Fuels 31:2024-2032

6. Addicoat M, Bennett T, Chapman K, Denysenko D, Dincă M, Doan H, Easun T, Eddaoudi M, Farha O, Gagliardi L, Haase F, Hajiahmadi Farmahini A, Hendon C, Jorge M, Kitagawa S, Lamberti C, Lee J-SM, Leus K, Li J, Lin W, Liu X, Lloyd G, Lu C, Ma S, Perez JPH, Ranocchiari M, Rosi N, Stassen I, Ting V, van der Veen M, Van Der Voort P, Vande Velde CML, Volkmer D, Vornholt S, Walsh A, Yaghi OM (2017) New directions in gas sorption and separation with MOFs: general discussion. Faraday Disc 201:175-194

7. Xie Y, Liu X, Ma X, Duan Y, Yao Y, Cai Q (2018) Small titanium-based MOFS prepared with the introduction of tetraethyl orthosilicate and their potential for use in drug delivery. ACS Appl Mater Interf 10:13325-13332

8. Schönfeld F, Meyer LV, Mühlbach F, Zottnick SH, Müller-Buschbaum K (2018) Optical isotherms as a fundamental characterization method for gas sensing with luminescent MOFs by comparison of open and dense frameworks. J Mater Chem C 6:2588-2595

9. Assen AH, Yassine O, Shekhah O, Eddaoudi M, Salama KN (2017) MOFs for the sensitive detection of ammonia: deployment of fcu-MOF thin films as effective chemical capacitive sensors. ACS Sensors 2:1294-1301

10. Wei J-Z, Wang X-L, Sun X-J, Hou Y, Zhang X, Yang D-D, Dong H, Zhang F-M (2018) Rapid and large-scale synthesis of IRMOF-3 by electrochemistry method with enhanced fluorescence detection performance for TNP. Inorg Chem 57:3818-3824

11. Eddaoudi M, Kim J, Rosi N, Vodak D, Wachter J, O'Keeffe M, Yaghi OM (2002) Systematic design of pore size and functionality in isoreticular MOFs and their application in methane storage. Science 295(5554):469-472

12. Britt D, Tranchemontagne D, Yaghi OM (2008) Metal-organic frameworks with high capacity and selectivity for harmful gases. Proc Natl Acad Sci USA 105:11623-11627
13. Millward AR, Yaghi Millward OM (2005) Metal-organic frameworks with exceptionally high capacity for storage of carbon dioxide at room temperature. J Am Chem Soc 127:17998-17999

14. Babarao R, Hu Z, Jiang J, Chempath S, Sandler SI (2007) Storage and separation of $\mathrm{CO}_{2}$ and $\mathrm{CH}_{4}$ in silicalite, $\mathrm{C} 168$ Schwarzite, and IRMOF-1: a comparative study from Monte Carlo simulation. Langmuir 23:659-666

15. Koukaras EN, Montagnon T, Trikalitis P, Bikiaris D, Zdetsis AD, Froudakis GE (2014) Toward efficient drug delivery through suitably prepared metal-organic frameworks: a firstprinciples study. J Phys Chem C 118:8885-8890

16. Phan NTS, Nguyen TT, Luu QH, Nguyen LTL (2012) PaalKnorr reaction catalyzed by metal-organic framework IRMOF-3 as an efficient and reusable heterogeneous catalyst. J Mol Catal A 363-364:178-185

17. Go H, Shun I, Yasuhiro U (2018) A palladium NNC-pincer complex as an efficient catalyst precursor for the Mizoroki-Heck Reaction. Adv Synth Catal 360:1833-1840

18. Zhou X, Guo X, Jian F, Wei G (2018) Highly efficient method for Suzuki reactions in aqueous media. ACS Omega 3:4418-4422

19. Rejc L, Gómez-Vallejo V, Alcázar J, Alonso N, Andrés JI, Arrieta A, Cossío FP, Llop J (2018) Negishi coupling reactions with [11 C] CH 3 I: a versatile method for efficient $11 \mathrm{C}-\mathrm{C}$ bond formation. Chem Commun 54:4398-4401

20. Liu Q, Xu M, Zhao J, Yang Z, Qi C, Zeng M, Xia R, Cao X, Wang B (2018) Microstructure and catalytic performances of chitosan intercalated montmorillonite supported palladium (0) and copper (II) catalysts for Sonogashira reactions. Int J Biol Macromol 113:1308-1315

21. Qi X, Sun H, Li X, Fuhr O, Fenske D (2018) Synthesis and catalytic activity of $N$-heterocyclic silylene (NHSi) cobalt hydride for Kumada coupling reactions. Dalton Trans 47:2581-2588

22. Gao J, Wang W, Zhang S, Xiao S, Zhan C, Yang M, Lu X, You W (2018) Distinction between PTB7-Th samples prepared from $\mathrm{Pd}$ (PPh 3 ) 4 and Pd 2 (dba) 3/P (o-tol) 3 catalysed stille coupling polymerization and the resultant photovoltaic performance. J Mater Chem A 6:179-188

23. Shi S, Nawaz KS, Zaman MK, Sun Z (2018) Advances in enantioselective $\mathrm{C}-\mathrm{H}$ activation/Heck reaction and Suzuki reaction. Catalysts 8:90

24. Kurandina D, Rivas M, Radzhabov M, Gevorgyan V (2018) Heck reaction of electronically diverse tertiary alkyl halides. Org Lett 20:357-360

25. Minatti A, Zheng X, Buchwald SL (2007) Synthesis of chiral 3 -substituted indanones via an enantioselective reductive-Heck reaction. J Org Chem 72:9253-9258

26. Wangqing K, Qian W, Jieping Z (2017) Water as a hydride source in palladium-catalyzed enantioselective reductive Heck reactions. Angew Chem Int Ed Engl 56:3987-3991

27. Xu B, Qian W, Jieping Z (2017) Palladium-catalyzed enantioselective Narasaka-Heck reaction/direct $\mathrm{C}-\mathrm{H}$ alkylation of arenes: Iminoarylation of alkenes. Angew Chem Int Ed Engl 56:9577-9581

28. Park T-H, Hickman AJ, Koh K, Martin S, Wong-Foy AG, Sanford MS, Matzger AJ (2011) Highly dispersed palladium(II) in a defective metal-organic framework: application to $\mathrm{C}-\mathrm{H}$ activation and functionalization. J Am Chem Soc 133:20138-20141

29. Servalli M, Ranocchiari M, Van Bokhoven JA (2012) Fast and high yield post-synthetic modification of metal-organic frameworks by vapor diffusion. Chem Commun 48:1904-1906

30. Xamena FXL, Cirujano FG, Corma A (2012) An unexpected bifunctional acid base catalysis in IRMOF-3 for Knoevenagel condensation reactions. Microporous Mesoporous Mater 157:112-117

31. Yuanbiao H, Tao M, Ping H, Dongshuang W, Zujin L, Rong C (2013) Direct C-H bond arylation of indoles with aryl boronic acids catalyzed by palladium nanoparticles encapsulated 
in mesoporous metal-organic framework. ChemCatChem 5:1877-1883

32. Wang X-L, Fan H-L, Tian Z, He E-Y, Li Y, Shangguan J (2014) Adsorptive removal of sulfur compounds using IRMOF-3 at ambient temperature. Appl Surf Sci 289:07-113

33. Wang S, Bromberg L, Schreuder-Gibson H, Hatton TA (2013) Organophophorous ester degradation by chromium(III) terephthalate metal-organic framework (MIL-101) chelated to $N, N$ dimethylaminopyridine and related aminopyridines. ACS Appl Mater Interf 5:1269-1278

34. Zhou X, Zhang Y, Yang X, Zhao L, Wang G (2012) Functionalized IRMOF-3 as efficient heterogeneous catalyst for the synthesis of cyclic carbonates. J Mol Catal A 361-362:12-16

35. Rodriguez J, Kuhn M (1996) Interaction of Zinc with transitionmetal surfaces: electronic and chemical perturbations induced by bimetallic bonding. J Phys Chem 100:381-389

36. Fasana A, Braichovic L (1982) Chemically driven diffusion of Pd in the surface region of $\mathrm{Zn}(0001)$ : an ultraviolet photoemission investigation. Surf Sci 120:239-250

37. Liang L, Nie L, Jiang M, Bie F, Shao L, Qi C, Zhang XM, Liu $X$ (2018) Palladium immobilized on in situ cross-linked chitosan superfine fibers for catalytic application in an aqueous medium. New J Chem 42:11023-11030

38. Zhao F, Bhanage BM, Shirai M, Arai M (2000) Heck reactions of iodobenzene and methyl acrylate with conventional supported palladium catalysts in the presence of organic and/and inorganic bases without ligands. Chem Eur J 6:843-848

39. Liu G, Hou M, Song J, Jiang T, Fan H, Zhang Z, Han B (2010) Immobilization of Pd nanoparticles with functional ionic liquid grafted onto cross-linked polymer for solvent-free Heck reaction. Green Chem 12:65-69
40. Burés J (2016) A simple graphical method to determine the order in catalyst. Angew Chem Int Ed Engl 55:2028-2031

41. Rosol M, Moyano A (2005) 1'-Carbopalladated-4-ferrocenyl1,3-oxazolines as catalysts for Heck reactions: further evidence in support of the $\mathrm{Pd}(0) / \mathrm{Pd}(\mathrm{II})$ mechanism. J Organomet Chem 690:2291-2296

42. Cassez A, Kania N, Hapiot F, Fourmentin S, Monflier E, Ponchel A (2008) Chemically modified cyclodextrins adsorbed on $\mathrm{Pd} / \mathrm{C}$ particles: new opportunities to generate highly chemoand stereoselective catalysts for Heck reaction. Catal Commun 9:1346-1351

43. Han W, Liu N, Liu C, Jin ZL (2010) A ligand-free Heck reaction catalyzed by the in situ-generated palladium nanoparticles in PEG-400. Chin Chem Lett 21:1411-1414

44. Phan NTS, van der Sluys M, Jones CW (2006) On the nature of the active species in palladium catalyzed Mizoroki-Heck and Suzuki-Miyaura couplings-homogeneous or heterogeneous catalysis. A critical review. Adv Synth Catal 348:609-679

45. Asrtruc D (2007) Palladium nanoparticles as efficient green homogeneous and heterogeneous carbon-carbon coupling precatalysts: a unifying view. Inorg Chem 46:1884-1894

46. Glasnov TN, Findenig S, Kappe CO (2009) Heterogeneous versus homogeneous palladium catalysts for ligandless Mizoroki-Heck reactions: a comparison of batch/microwave and continuous-flow processing. Chem Eur J 15:1001-1010

Publisher's Note Springer Nature remains neutral with regard to jurisdictional claims in published maps and institutional affiliations.

\section{Affiliations}

\section{Ayat Nuri ${ }^{1,2} \cdot$ Nemanja Vucetic $^{2} \cdot$ Jan-Henrik Smått ${ }^{3} \cdot$ Yagoub Mansoori $^{1} \cdot$ Jyri-Pekka Mikkola $^{2,4}$. Dmitry Yu. Murzin ${ }^{2} \mathbb{D}$}

1 Department of Applied Chemistry, Faculty of Science, University of Mohaghegh Ardabili, Ardabil, Iran

2 Johan Gadolin Process Chemistry Centre, Laboratory of Industrial Chemistry, Åbo Akademi University, Biskopsgatan 8, 20500 Turku, Finland
3 Department of Physical Chemistry, Åbo Akademi University, Porthansgatan 3-5, 20500 Turku, Finland

4 Technical Chemistry, Department of Chemistry, Chemical-Biological Center, Umeå University, 90187 Umeå, Sweden 